BMJ Open Diabetes Research \& Care

\title{
Diabetic muscle infarction: a systematic review
}

\author{
William B Horton, ${ }^{1}$ Jeremy S Taylor, ${ }^{1}$ Timothy J Ragland, ${ }^{2}$ Angela R Subauste ${ }^{1,3}$
}

To cite: Horton WB, Taylor JS, Ragland TJ, et al. Diabetic muscle infarction: a systematic review. BMJ Open Diabetes Research and Care 2015;3:e000082. doi:10.1136/bmjdrc-2015000082

Received 13 January 2015 Revised 1 March 2015 Accepted 4 March 2015

\section{(D) CrossMark}

\footnotetext{
${ }^{1}$ Department of Medicine, University of Mississippi Medical Center, Jackson, Mississippi, USA

2Department of Radiology, University of Mississippi Medical Center, Jackson, Mississippi, USA ${ }^{3}$ Division of Endocrinology, University of Mississippi Medical Center, Jackson, Mississippi, USA
}

Correspondence to Dr Angela R Subauste; asubauste@umc.edu

\section{ABSTRACT}

Context: Diabetic muscle infarction (DMI) is a rare complication associated with poorly controlled diabetes mellitus. Less than 200 cases have been reported in the literature since it was first described over 45 years ago. There is no clear 'standard of care' for managing these patients.

Evidence acquisition: PubMed searches were conducted for 'diabetic muscle infarction' and 'diabetic myonecrosis' from database inception through July 2014. All articles identified by these searches were reviewed in detail if the article text was available in English.

Evidence synthesis: The current literature exists as case reports or small case series, with no prospective or higher-order treatment studies available. Thus, an evidence-based approach to data synthesis was difficult. The available literature is presented objectively with an attempt to describe clinically relevant trends and findings in the diagnosis and management of DMI. Conclusions: Early recognition of DMI is key, so appropriate treatment can be initiated. MRI is the radiological study of choice. A combination of bed rest, glycemic control, and non-steroidal anti-inflammatory drug therapy appears to yield the shortest time to symptom resolution and the lowest risk of recurrence.

\section{INTRODUCTION}

Diabetic muscle infarction (DMI), also termed diabetic myonecrosis, is a rare microangiopathic complication associated with poorly controlled diabetes mellitus (DM). First described by Angervall and Stener in $1965,{ }^{1}$ DMI classically presents as acute pain and swelling of the affected muscle, most often in the lower extremities. ${ }^{2}$ DMI usually presents in patients with a longstanding history of diabetes and associated complications of poor glycemic control, including nephropathy, retinopathy, and/ or neuropathy. ${ }^{2}$

Although diabetes is a very common disease, DMI is a relatively uncommon complication. Less than 200 cases have been reported since it was initially described over 45 years ago. ${ }^{3}$ Most of the available literature exists as case reports or small case series, with no clear consensus on diagnostic

\section{Key messages}

Diabetic muscle infarction (DMI) is a rare and likely under-recognized complication of type 1 and type 2 diabetes mellitus.

- DMI presents as acute muscular pain and swelling, particularly in the lower extremities.

- MRI is the imaging study of choice.

- Non-steroidal anti-inflammatory drug therapy is associated with the shortest recovery time and lowest risk of recurrence.

criteria or management. This clinical review seeks to summarize the available literature on patient demographics, clinical presentation, diagnosis, and management of DMI.

\section{METHODS}

\section{Search strategy and eligibility criteria}

PubMed searches were conducted for 'diabetic muscle infarction' and 'diabetic myonecrosis' from database inception through July 2014. All articles identified by these searches were reviewed if the article text was available in English. All titles and abstracts of papers identified by the searches were assessed for inclusion by one reviewer. Data extraction was completed independently by two reviewers. Case reports and case series were included in the analysis if a diagnosis of DMI was reported. In all, 87 total references with 126 initial episodes of DMI were included. ${ }^{3-89}$ A total of 11 references were excluded due to lack of English translation or text. Additionally, 44 episodes of DMI recurrence were noted in these case reports and series. Therefore, by the parameters of our search, there have been 170 episodes of DMI reported in the English language medical literature over the past 48 years (figure 1 ).

\section{Data synthesis and analysis}

The following were tabulated for each case: age, gender, location of affected area, history of trauma, fever, diabetes type, glycated hemoglobin (HbA1c), diabetes duration, presence of microvascular complications, laboratory tests and procedures performed, 


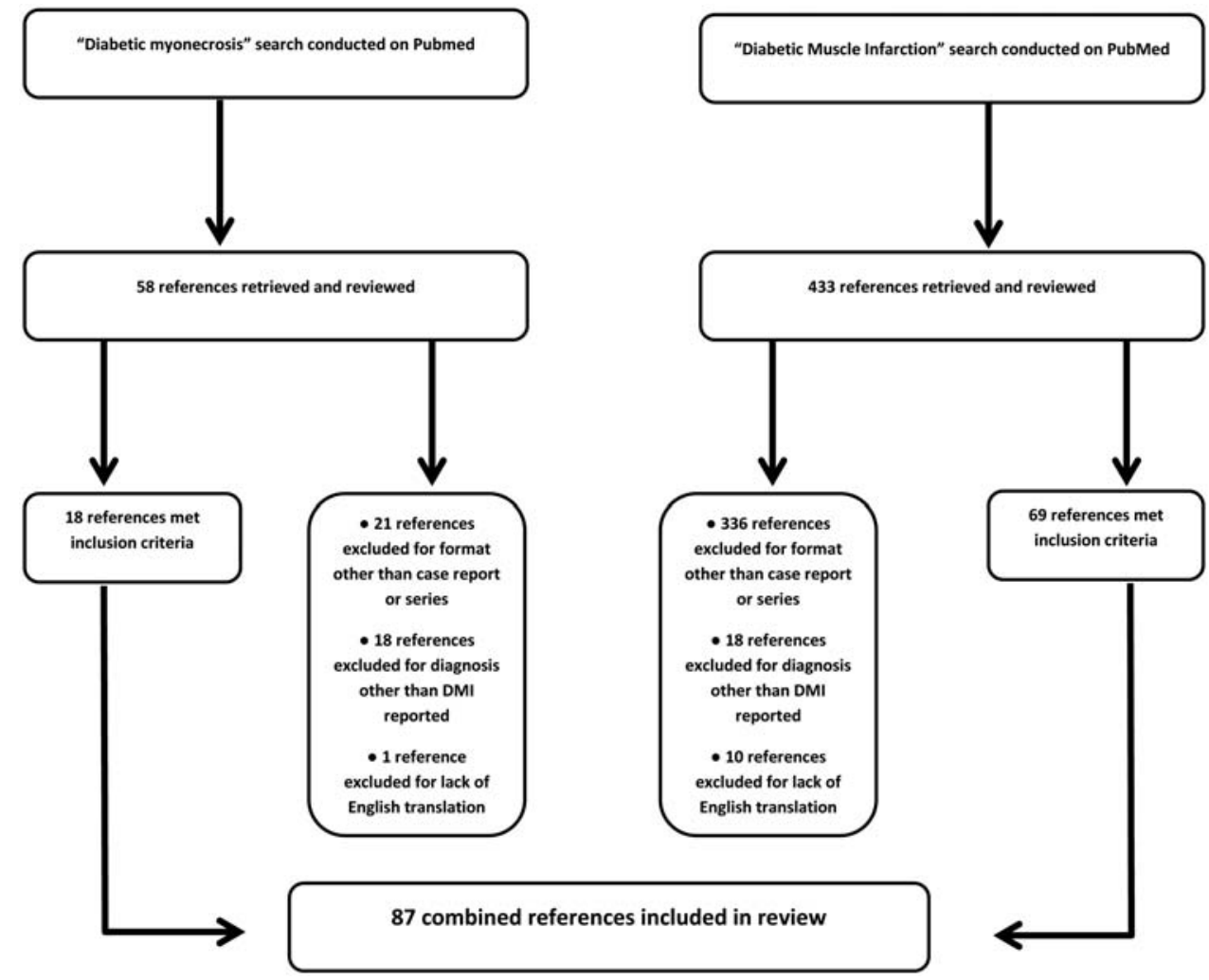

Figure 1 Flow diagram of the review and selection of cases (DMI, diabetic muscle infarction).

imaging studies, treatment modalities, time to resolution, and recurrence. Time to resolution is presented as 'days'. All cases in which time was presented in weeks or months were converted to days.

Continuous data were summarized as mean and range. Categorical data were reported as the number of subjects, and percentages were calculated using the following formula: number of patients with a given characteristic/ total number of patients with available information about that given characteristic $\times 100$. Between groups analysis was performed by a Wilcoxon-Mann-Whitney test and a $\mathrm{p}<0.05$ was considered statistically significant. No author from these studies was contacted to retrieve missing data.

\section{PATIENT CHARACTERISTICS}

Of the 126 initial cases of DMI reported in the literature, 68 occurred in females $(54 \%)$. The mean age of presentation for all cases was 44.6 years (20-67), though mean age did vary by diabetes type. The mean age of presentation for patients with type 1 DM (T1DM) was 35.9 (20-65) years, while the mean age for those with type 2 DM (T2DM) was 52.2 (34-67) years. A total of 108 cases reported diabetes type at the time of diagnosis. Of those 108 cases, $54(50 \%)$ had T2DM while 45 $(41.7 \%)$ had T1DM. The mean DM duration at the time of DMI diagnosis was 18.9 (5-33) years for T1DM and 11.0 (1-25) years for T2DM. HbA1c values were reported at the time of DMI diagnosis in 51 cases and mean value was $9.34 \%$ (5-21). Of the 126 cases, a total of 117 referenced known diabetic complications at the time of diagnosis. Fifty-five cases $(46.6 \%)$ had concurrent retinopathy, nephropathy, and neuropathy. Seventy-seven cases $(65.8 \%)$ had at least two complications, indicating that DMI is often seen in patients with advanced diabetes. The most common microvascular complication associated with DMI is nephropathy, present in $75 \%$ of DMI cases.

\section{PATHOPHYSIOLOGY}

The pathophysiology of DMI is still unclear. Some have theorized that it is secondary to atherosclerosis, diabetic microangiopathy, vasculitis with thrombosis, or ischemia-reperfusion injury. ${ }^{40}$ One suggested mechanism attributes DMI to thromboembolic events secondary to microvascular endothelial damage leading to tissue ischemia, which triggers an inflammatory cascade leading to local tissue damage and ischemic necrosis. Reperfusion of ischemic tissues associated with endothelium dysfunction is manifested as impaired endotheliumdependent dilation in arterioles along with increased oxygen radicals, with less nitric oxide, following reperfusion. The resulting imbalance between superoxide and nitric oxide in endothelial cells leads to the production and release of inflammatory mediators (tumor necrosis factor and platelet-activating factor) along with increased biosynthesis of adhesion molecules. ${ }^{90}$ The inflammatory cascade increases intracompartmental ischemia from edema with further worsening of tissue necrosis. ${ }^{73}$ 
Pedicelli et $a \tilde{l}^{0}$ described the case of a patient with T1DM with a longstanding history of diabetes and recurrent episodes of DMI. MR angiography obtained with gadolinium-enhanced sequences, in the arterial phase, showed an increased number of visible arterial branches. This MR angiography pattern of increased arterial branches was consistent with dilation of the muscular arterioles. Chester and Banker ${ }^{63}$ reviewed six cases. In two cases, they observed severe distal peripheral vascular disease. The authors proposed that the initial ischemia could cause a swelling that through increased pressure could compromise blood flow, leading to DMI.

Some authors have identified alterations in the coagulation-fibrinolysis system in the form of hypercoagulability and vascular endothelial damage in DMI. ${ }^{67}$ Palmer and Greco ${ }^{47}$ described two patients with DMI and antiphospholipid syndrome. Indeed, there is evidence suggesting that patients with T1DM are at increased risk for the presence of anticardiolipin antibodies. This has been supported by findings from epidemiological studies as well as by genome-wide association studies. ${ }^{91-93}$ For example, the human chromosomal 12q24 locus, with the gene $\mathrm{SH}_{2 \mathrm{~B} 3}$ in its core, has been linked to autoimmune disorders includingT1DM, celiac disease, thrombotic antiphospholipid syndrome, hypothyroidism, and vitiligo. While there is an association between T1DM and anticardiolipin antibodies, this has not been the case for T2DM. ${ }^{94}$ Further studies will need to determine if patients with DMI have a high prevalence of anticardiolipin antibodies.

It has also been suggested that vasculitis could be a factor as patients with diabetes are known to be susceptible to inflammatory vasculopathy. ${ }^{61}$ It is important to point out that patients with inflammatory vasculopathy overall differ from patients with DMI as a group as they are usually older patients with T2DM with no extensive microvascular complications. ${ }^{2}{ }^{61}$

\section{DIAGNOSIS}

DMI should be suspected in any patient with diabetes who presents with acute muscular pain and swelling, particularly in the lower extremities. A history of poorly controlled diabetes with complications should increase diagnostic suspicion. Patients usually do not report trauma (96.3\%) and are afebrile on presentation (89\%). Deep venous thrombosis (DVT) should be ruled out in the diagnostic workup for DMI. Eighty-two of 83 $(98.8 \%)$ cases in this review reported negative DVT ultrasonography studies.

Routine laboratory investigations for DMI are relatively non-specific. ${ }^{2}{ }^{73}$ White cell count (WCC) values were reported in 113 cases. WCC was within normal limits in $56.6 \%$ of cases, elevated in $42.5 \%$ of cases, and decreased in $0.9 \%$ of cases.

Creatine kinase (CK) values were reported in 67 of 126 cases. The CK values were within normal limits in $68.4 \%$ of cases. Erythrocyte sedimentation rate (ESR) and $\mathrm{C}$ reactive protein (CRP) levels do appear to be somewhat useful markers to aid in the diagnosis of DMI. ESR was reported in 60 of the 126 cases; values were elevated in $83.3 \%$ of cases. CRP was elevated in 27 (90\%) of the 30 cases reported. Autoimmune workup was performed only on a small number of cases. One case returned positive testing for a lupus anticoagulant and two cases reported positive anticardiolipin antibody tests. Cultures (blood, urine, and/or wound) were obtained and reported as negative in 38 of 39 cases $(97.4 \%)$. The one positive culture reported was collected from urine and likely unrelated to the DMI diagnosis. Table 1 lists all laboratory findings reported in our review.

Initial muscular symptoms with adequate localization were recorded in 111 cases (figure 2). Thigh pain/swelling was most commonly reported (79 cases; $71.2 \%$ ). Calf pain/swelling was noted in 17 cases $(15.3 \%)$ and upper arm pain/swelling was noted six times (5.4\%). Forty-four episodes $(34.9 \%)$ of DMI recurrence were noted in our review and $61.4 \%$ of these recurrences were noted in a different location/muscle group than initial presentation.

Muscle biopsy can provide a definitive diagnosis but is currently not recommended due to the risk for procedure-associated complications and an associated increase in time to symptomatic improvement. ${ }^{2} 1060$ Biopsy should be reserved for cases in which the clinical presentation is atypical or when appropriate treatment fails to elicit improvement. ${ }^{2} 63$ Biopsy usually demonstrates areas of muscle necrosis and edema. Later findings include the presence of fibrotic tissue and muscle fiber regeneration with lymphocytic infiltration. Biopsy was performed in 63 of 119 cases. The mean time to reported symptom resolution was significantly longer when biopsy was performed (60.8 days) as opposed to when it was avoided (29.5 days; $\mathrm{p}<0.001)$ in this review.

MRI is the modality of choice for radiological evaluation of patients with suspected DMI. ${ }^{4}{ }^{95}$ MRI is sensitive and specific enough to make the diagnosis. ${ }^{60}$ Typical MRI features include a hyperintense signal on T2-weighted images and an isointense to hypointense signal on T1-weighted images from the affected muscle, with associated perifascial, perimuscular, and/or subcutaneous edema $^{26095}$ (figure 3). MRI was performed in 103 included cases. Edema with T2 hyperintensity was noted in $76.8 \%$ of cases while $\mathrm{T} 1$ isointensity or hypointensity was reported in $14.6 \%$ of cases. One hundred and forty cases reported specific infarcted muscle groups identified by MRI. The most commonly affected muscle was the vastus medialis, which was identified in 25 cases $(17.9 \%)$. Other common locations included the vastus lateralis $(15 \%)$, the vastus intermedius $(7.1 \%)$, the rectus femoris $(6.4 \%)$, the soleus $(5.7 \%)$, and the gastrocnemius (5\%).

Bedside ultrasonography has also been recommended as a preferred diagnostic technique. ${ }^{96}$ Sonographic findings include a well-marginated, hypoechoic intramuscular 
Table 1 Laboratory investigations performed on initial presentation

\begin{tabular}{lcllll}
\hline Laboratory & Mean value (range; SD) & Normal/negative & Elevated/positive & Not reported & Decreased \\
\hline WCC $\left(\times 10^{9} / \mathrm{L}\right)$ & $11.5(3.6-32 ; \pm 4.76)$ & $64(56.6 \%)$ & $48(42.5 \%)$ & 13 & $1(0.9 \%)$ \\
CRP $(\mathrm{mg} / \mathrm{L})$ & $156.4(0.03-524 ; \pm 130)$ & $3(10 \%)$ & $27(90 \%)$ & 96 & N/A \\
ESR $(\mathrm{mm} / \mathrm{h})$ & $86.6(1-153 ; \pm 40.5)$ & $10(16.7 \%)$ & $50(83.3 \%)$ & 66 & N/A \\
CK $(\mathrm{IU} / \mathrm{L})$ & $709.7(10-11000 ; \pm 1950)$ & $67(68.45)$ & $31(31.6 \%)$ & 28 & $\mathrm{~N} / \mathrm{A}$ \\
\hline
\end{tabular}

CK, creatine kinase; CRP, C reactive protein; ESR, erythrocyte sedimentation rate; N/A, not applicable; WCC, white cell count.

lesion. Internal linear, echogenic structures coursing through the lesion have also been described. It has been suggested that unlike an abscess or necrotic tumor, in patients with DMI there is usually an absence of internal motion or swirling of fluid with transducer pressure and a lack of a predominantly anechoic area.

\section{MANAGEMENT}

Previous studies have recommended treatment consisting of rest, analgesia, and rigorous glycemic control. $^{2} 607597$ One study showed low-dose aspirin shortened recovery time to 39 days from 57 days in those treated with rest and analgesia alone. Surgical intervention increased recovery time to 91 days in the same study and is generally not recommended. ${ }^{98}$ In this review, the mean time to symptom resolution for surgery was 68.7 days, with resolution defined as the disappearance of pain and swelling of the affected area. Physiotherapy (PT) has been a debated component of management. Some authors have recommended avoidance of PT because of prolonged recovery time ${ }^{63}$ while
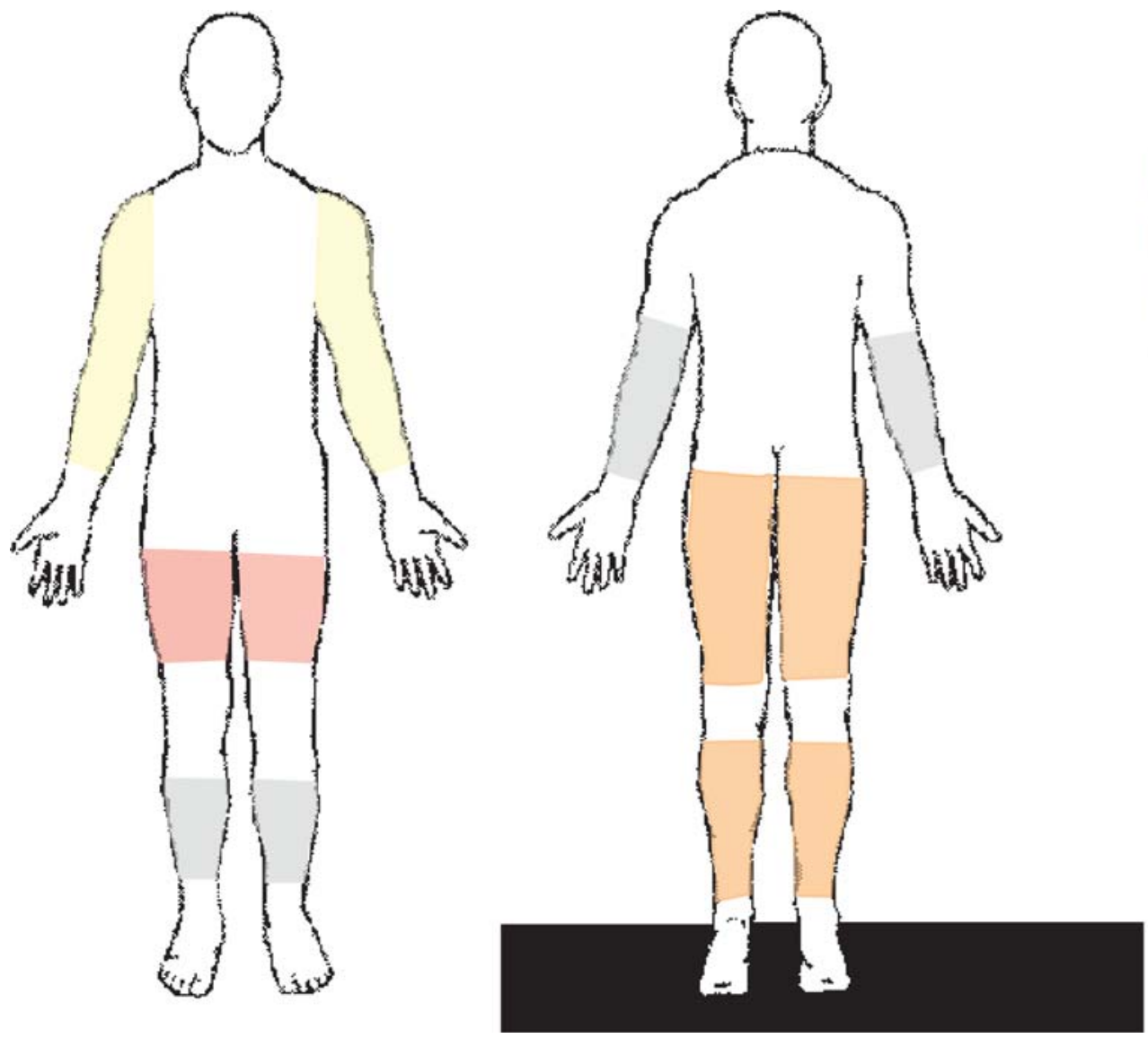

Figure 2 Diabetic muscle infarction affected regions by percentages. The most commonly affected region is the front thigh, followed by the calf and back thigh. Affected muscle groups: vastus medialis $(25 ; 17.9 \%)$, vastus lateralis $(21 ; 15 \%)$, vastus intermedius $(10 ; 7.1 \%)$, rectus femoris $(9 ; 6.4 \%)$, soleus $(8 ; 5.7 \%)$, gastrocnemius $(7 ; 5 \%)$, adductor magnus $(6 ; 4.3 \%)$, biceps femoris $(6 ; 4.3 \%)$, sartorius $(5 ; 3.6 \%)$, gracilis $(4 ; 2.9 \%)$, tibialis anterior $(4 ; 2.9 \%)$, gluteus maximus $(3 ; 2.1 \%)$, peroneus brevis $(3 ; 2.1 \%)$, semimembranosus $(3 ; 2.1 \%)$, deltoid $(2 ; 1.4 \%)$, brachioradialis $(2 ; 1.4 \%)$, tibialis posterior $(2 ; 1.4 \%)$, pectineus $(1 ; 0.7 \%)$, external obturator $(1 ; 0.7 \%)$, flexor digitorum longus $(1 ; 0.7 \%)$, flexor hallucis longus $(1 ; 0.7 \%)$, tensor fasciae latae $(1 ; 0.7 \%)$, triceps $(1 ; 0.7 \%)$, biceps $(1 ; 0.7 \%)$, brachialis $(1 ; 0.7 \%)$, coracobrachialis $(1 ; 0.7 \%)$, pronator teres $(1 ; 0.7 \%)$, pectoralis major $(1 ; 0.7 \%)$, supraspinatus $(1 ; 0.7 \%)$, subscapularis $(1 ; 0.7 \%)$, adductor hallucis $(1 ; 0.7 \%)$, extensor hallucis longus $(1 ; 0.7 \%)$, plantaris $(1 ; 0.7 \%)$, obturator $(1 ; 0.7 \%)$, gluteus medius $(1 ; 0.7 \%)$, gluteus minimus $(1 ; 0.7 \%)$, semitendinosus $(1 ; 0.7 \%)$. 


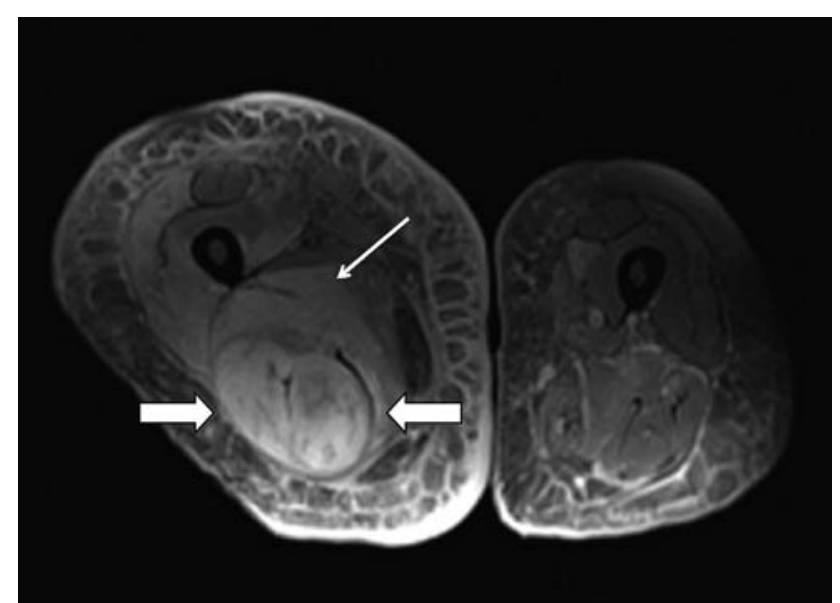

Figure 3 Imaging studies. Proton density fat-saturated MRI sequence demonstrates an increased signal within the semimembranosus and biceps femoris musculature (large arrows) and the adductor magnus muscle (thin arrow) consistent with edema due to early muscle infarction. MRI was performed in the 103 cases included. The findings identified included T2 hyperintensity (86; 76.8\%), T1 hypointensity $(7 ; 6.3 \%)$, T1 isointensity $(8 ; 7.1 \%)$, and T1 hyperintensity $(2 ; 1.8 \%)$. No MRI was performed in 23 cases (18.3\%).

others have not observed this in their study populations. ${ }^{98} 99$ In this review, patients receiving PT had the longest mean time to symptom resolution at 76.5 days. Recovery times for other treatment modalities were 41.7 days for patients receiving bed rest, and 28.5 days with supportive care/bed rest plus a non-steroidal antiinflammatory drug (NSAID). Supportive care included glycemic control and pain management. These data were only statistically significant for PT compared with NSAID treatment and surgery compared with NSAID treatment. Overall, 34 patients were treated with bed rest, 11 received PT, 10 were treated with surgical intervention, and 10 received NSAID in addition to supportive care or bed rest. Nearly all patients received rigorous glycemic control following diagnosis of DMI. Patients who received combined therapy with NSAID or bed rest plus surgery or PT were not included in the above calculations to avoid confounding. There was a similar percentage of patients receiving biopsies among treatment groups: $30 \%$ treated with NSAID therapy, 33\% with supportive care, $47 \%$ with bed rest, and $54.5 \%$ with PT. Table 2 details treatments received by patients included in this review.

As mentioned previously, patients with DMI are at high risk for recurrence. Thus, therapy should be aimed at reducing the recovery time as well as at minimizing the risk of recurrence. As with any other diabetes complication, adequate glycemic control would be expected to decrease the risk of complications. We were unable to obtain data regarding subsequent glycemic control and risk of recurrence from the reported cases. Interestingly, we found that the recovery time was not only longer for patients undergoing surgery, but the risk of recurrence was also high $(50 \%)$. The group receiving PT demonstrated a low risk of recurrence (18\%). Again, as with recovery time, the NSAID group had the lowest risk of recurrence (10\%; table 2 ). Regarding NSAID therapy, aspirin was the most commonly used NSAID. The doses ranged from 81 to $325 \mathrm{mg}$ a day.

\section{DISCUSSION}

DMI is a rare complication of DM that is likely underrecognized. Unlike previous reviews by Trujillo-Santos ${ }^{2}$ and Kapur et $a l^{28}$ we did not demonstrate a T1DM or female predominance in patients with DMI. On the other hand, our data are consistent with results of previous reviews $^{2} 2860$ which reported DM complication rates similar to those identified in our study.

DMI presents with the acute onset of muscular pain and swelling, most commonly in the thigh without a history of trauma or fever. Previous reviews noted similar findings as the ones described here, with thigh pain/ swelling being the initial presentation in $83.7 \%,{ }^{2} 75 \%,{ }^{60}$ and $80 \%{ }^{28}$ Calf pain/swelling was the second most common presentation, identified in $19.28 \%^{2}$ and $15 \%^{60}$ of previous studies.

Routine laboratory investigations are often nonspecific, though inflammatory markers are elevated in

Table 2 Treatment modalities received by patients with DMI

\begin{tabular}{|c|c|c|c|c|c|c|}
\hline Treatment & $\begin{array}{l}\text { Mean patient age, } \\
\text { years (range; SD) }\end{array}$ & $\begin{array}{l}\text { Gender } \\
\text { (male: } \\
\text { female) }\end{array}$ & $\begin{array}{l}\text { Mean hemoglobin } \\
\text { A1c \% (range; SD) }\end{array}$ & $\begin{array}{l}\text { Biopsy } \\
\text { rate }(\%)\end{array}$ & $\begin{array}{l}\text { Mean time to } \\
\text { symptom } \\
\text { resolution, days } \\
\text { (range; SD) }\end{array}$ & $\begin{array}{l}\text { Recurrence } \\
\text { rate (\%) }\end{array}$ \\
\hline Surgery $(n=10)$ & $43.8(27-61 ; \pm 10)$ & $2: 8$ & $8.0(6.4-11.7 ; \pm 2.4)$ & 100 & $81.6(25-120 ; \pm 40)^{\star}$ & 50 \\
\hline Bed rest $(n=34)$ & $44.9(21-81 ; \pm 13.5)$ & $16: 18$ & $9.3(7.1-13.9 ; \pm 2.3)$ & 47 & $41.7(5-120 ; \pm 33)$ & 32 \\
\hline NSAID therapy $(n=10)$ & $33.2(20-57 ; \pm 12)$ & $3: 7$ & $9.4(5-15.5 ; \pm 3.4)$ & 30 & $28.5(10-60 ; \pm 14)$ & 10 \\
\hline Physiotherapy $(n=11)$ & $46.1(25-67 ; \pm 14)$ & $7: 4$ & $9.3(6.4-15.8 ; \pm 3.7)$ & 54.5 & $76.5(21-180 ; \pm 60)^{*}$ & 18 \\
\hline
\end{tabular}


most cases. The mean HbAlc in this review was $9.34 \%$. Defining the state of glycemic control in patients with DMI is limited by the fact that HbAlc was only reported in $40 \%$ of cases. Patients with DMI are at high risk of recurrence. Consistent with our findings of a $34.9 \%$ recurrence rate, a previous study noted a DMI recurrence rate of $45 \% .^{28}$ The underlying pathophysiology is unclear and factors such as atherosclerosis, diabetic microangiopathy, vasculitis, and ischemia-reperfusion injury have been considered as possible causes. There are reports linking DMI with antiphospholipid syndrome. Given the long-term implications, antiphospholipid syndrome should be ruled out, especially in patients with T1DM, as this group appears to be at increased risk. ${ }^{100}$ MRI is the diagnostic study of choice for radiological evaluation of patients with suspected DMI. Typical MRI findings include a hyperintense signal on T2-weighted images with associated muscular edema.

The optimal treatment plan for DMI has not yet been identified, and current treatment recommendations are based on limited evidence. The data included in this review supports a combination of bed rest, glycemic control, and NSAID therapy as preferred treatment for DMI. Avoidance of surgery and PT during the acute phase could be recommended given the longer time to resolution. While the difference in mean time to symptom resolution was only significant for NSAID therapy versus PT and surgery, there was a trend toward longer resolution for bed rest versus NSAID therapy. NSAID therapy associates with the lowest rate of recurrence. It is important to mention that given the retrospective nature of this report, we are unable to determine if the reason for the prolonged recovery time in surgical patients is possibly due to this group suffering from a more severe muscle infarction. Surgical consultation might be required in some cases as previously reported. ${ }^{41} 2426283743474851$

It is not surprising that NSAIDs could be effective as it has become clear that diabetes is a prothrombotic state due to a combination of platelet dysfunction, inflammation, and endothelial dysfunction. NSAIDs, such as aspirin and salicylate, exert their activity by inhibiting cyclo-oxygenase enzyme-mediated eicosanoid formation. ${ }^{101}$ These lead to an antithrombotic and antiinflammatory effect. Preclinical studies have demonstrated that aspirin has a role in macrovascular complications as well as in microvascular complications as it prevents capillary cell apoptosis and vessel degeneration in dogs and rats with diabetes. ${ }^{102} 103$ In clinical studies, aspirin has been shown to reduce the development of microaneurysms in patients with early retinopathy. ${ }^{104}$ As mentioned previously, antiphospholipid syndrome should be ruled out in DMI, particularly in patients with T1DM. Aspirin is also indicated under these circumstances. The literature regarding the use of anticoagulants such as heparin in patients with DMI is very limited.

The results of this review also suggest that PT should be avoided (at least in the acute phase), as well as invasive procedures, due to the potential increase in recovery time. Given that prolonged bed rest can lead to deconditioning and increases the risk for thromboembolic disease, we would recommend that PT be started once patients are discharged from the hospital. This will minimize the risk of symptom exacerbation in the acute phase while potentially decreasing the risk of recurrence later on.

The primary limitation of this study, as with any overview, is that the heterogeneity in reporting parameters by the various cases could not be controlled. Thus, the scope of complications reported, treatment regimens, and the outcome definitions are not the same across reports. This study also involves a relatively small sample size. The potential source of bias in this review includes the performance of muscle biopsy in some cases. It is possible that the significantly shortened time to symptom resolution between the NSAID and PT treatment groups was due to a smaller percentage of NSAID patients undergoing biopsy ( $30 \%$ of NSAID patients vs $54.5 \%$ of PT patients received biopsy). Another potential source of bias is the over-representation of positive diagnostic testing due to the under-reporting of negative tests.

Taken together, DMI is a complication of DM with a high risk of recurrence. Invasive procedures such as muscle biopsy and surgery appear to prolong recovery time. These results support the use of NSAID therapy as it shortens the time to symptom resolution while decreasing the risk of recurrence. Future studies should further investigate the role of NSAID in the management of DMI.

Contributors WBH wrote the manuscript and researched the data. JST researched the data and edited the manuscript. TJR reviewed and edited the manuscript. ARS is the guarantor.

\section{Competing interests None declared.}

Provenance and peer review Not commissioned; externally peer reviewed.

Data sharing statement No additional data are available.

Open Access This is an Open Access article distributed in accordance with the Creative Commons Attribution Non Commercial (CC BY-NC 4.0) license, which permits others to distribute, remix, adapt, build upon this work noncommercially, and license their derivative works on different terms, provided the original work is properly cited and the use is non-commercial. See: http:// creativecommons.org/licenses/by-nc/4.0/

\section{REFERENCES}

1. Angervall L, Stener B. Tumoriform focal muscular degeneration in two diabetic patients. Diabetologia 1965;1:39-42.

2. Trujillo-Santos AJ. Diabetic muscle infarction: an underdiagnosed complication of long-standing diabetes. Diabetes Care 2003;26:211-15.

3. Iyer SN, Drake AJ III, West RL, et al. Diabetic muscle infarction: a rare complication of long-standing and poorly controlled diabetes mellitus. Case Rep Med 2011;2011:407921.

4. De Vlieger G, Bammens B, Claus F, et al. Diabetic muscle infarction: a rare cause of acute limb pain in dialysis patients. Case Rep Nephrol 2013;2013:931523.

5. Yu CP, Liu TH, Wang B, et al. Diabetic muscle infarction in a patient admitted to the cardiac ward. Intern Med 2014;53:1227-9.

6. Mokta JK, Mokta K, Panda PK, et al. Diabetic muscle infarction: an unrecognised complication of diabetes-a case report from 
subhimalayan region of India. Indian J Endocrinol Metab 2013;17 (Suppl 3):S667-9.

7. Litvinov IV, Radu A, Garfield N. Diabetic muscle infarction in a 57 year old male: a case report. BMC Res Notes 2012;5:701.

8. Arroyave JA, Aljure DC, Canas CA, et al. Diabetic muscle infarction: two cases: one with recurrent and bilateral lesions and one with usual unilateral involvement. J Clin Rheumatol 2013;19:126-8.

9. Fatemi A, Samadi G, Hekmatnia A, et al. A diabetic woman with a swollen forearm. $J$ Res Med Sci 2012;17:892-3.

10. Shenavandeh S, Anushiravani A, Nazarinia MA. Diabetic muscle infarction and diabetic dermopathy two manifestations of uncontrolled prolong diabetes mellitus presenting severe leg pain and leg skin lesions. J Diabetes Metab Disord 2014;13:38.

11. Huang $\mathrm{E}$, Ho CF, Yip PK, et al. Diabetic muscle infarction in a patient with acute embolic stroke. Neurol Sci 2010;31:345-7.

12. Choudhury GD, Prakash S, Misra R, et al. An unusual case of knee monoarthritis. Int J Rheum Dis 2009;12:158-60.

13. Karalliedde J, Vijayanathan S, Thomas S. Painful foot drop; a presentation of diabetic muscle infarction. Diabet Med 2010;27:958-9.

14. Ucan H, Alemdaroglu E, Yoldas TK, et al. Diabetic muscular infarct: an unusual cause of extremity pain and dysfunction. Rheumatol Int 2012;32:525-8.

15. Deimel GW, Weroha JS, Rodriguez-Porcel M. 51-year-old hospitalized man with a painful leg. Mayo Clin Proc 2011;86:241-4.

16. Qasem A, Tanha F, Briemberg H. A case of diabetic muscle infarction. Can J Neurol Sci 2009;36:651-3.

17. Parmar MS. Diabetic muscle infarction. BMJ 2009;338:b2271.

18. Chang $\mathrm{YH}$, Yen FC, Hsieh MC, et al. Diabetic muscle infarction in association with terlipressin therapy: a case report. Kaohsiung $J$ Med Sci 2009;25:25-8.

19. Joshi R, Reen B, Sheehan H. Upper extremity diabetic muscle infarction in three patients with end-stage renal disease: a case series and review. J Clin Rheumatol 2009;15:81-4.

20. Schattner A, Zornitzki T, Adi M, et al. Painful swelling in the thigh: diabetic muscle infarction. CMAJ 2009;180:72-4.

21. Naderi AS, Farsian FN, Palmer BF. Diabetic muscle necrosis J Diabetes Complications 2008;22:150-2.

22. Macgregor JL, Chan $\mathrm{P}$, Schneiderman $\mathrm{PI}$, et al. Diabetic muscle infarction. Arch Dermatol 2007;143:1456-7.

23. Lim YW, Thamboo TP. Diabetic muscle infarction of the peroneus brevis: a case report. J Orthop Surg (Hong Kong) 2005;13:314-16.

24. Sahin I, Taskapan C, Taskapan H, et al. Diabetic muscle infarction: an unusual cause of muscle pain in a diabetic patient on hemodialysis. Int Urol Nephrol 2005;37:629-32.

25. Mikhail N, Cope D. Visual vignette. Diabetic muscle infarction. Endocr Pract 2004;10:165.

26. Lentine KL, Guest SS. Diabetic muscle infarction in end-stage renal disease. Nephrol Dial Transplant 2004;19:664-9.

27. Joshi R, Vargas R. Diabetic muscle infarction in renal transplantation. Transplantation 2004;77(2):321.

28. Kapur S, Brunet JA, McKendry RJ. Diabetic muscle infarction: case report and review. J Rheumatol 2004;31:190-4.

29. Gee R, Munk PL, O'Connell JX, et al. Diabetic muscle infarction: case report. Can Assoc Radiol J 2003;54:296-8.

30. Ahmed HN, Chhaya SK, Makdissi A, et al. Diabetic muscle infarction: case report of a rare complication. Am J Med 2007;120: e3-5.

31. Mathew A, Reddy IS, Archibald C. Diabetic muscle infarction. Emerg Med J 2007:24:513-14.

32. Glauser SR, Glauser J, Hatem SF. Diabetic muscle infarction: a rare complication of advanced diabetes mellitus. Emerg Radiol 2008;15:61-5.

33. Theodoropoulou E, Chelioti E, Revenas K, et al. Diabetic muscle infarction after kidney and pancreas transplantation: case report and literature review. Transplant Proc 2006;38:3147-50.

34. Lin CS, Huang GS, Chen CC, et al. Diabetic muscle infarction. Intern Med J 2006;36:748-9.

35. Kermani T, Baddour LM. Diabetic muscle infarction mistaken for cellulitis. Ann Intern Med 2006;145:555-6.

36. Cardillo S, Huse JT, Igbal N. Diabetic muscle infarction of the forearm in a patient with long-standing type 1 diabetes. Endocr Pract 2006;12:188-92.

37. Woolley SL, Smith DR. Acute compartment syndrome secondary to diabetic muscle infarction: case report and literature review. Eur J Emerg Med 2006;13:113-16.

38. Boulman N, Schapira D, Militianu D, et al. Diabetic muscle infarction. Isr Med Assoc J 2003;5:669-70.

39. Ali A, Conti M, Massucco $P$, et al. Diabetic muscle infarction associated with multiple autoimmune disorders, IgA deficiency and a catastrophically poor glycaemic control: a case report. Diabetes Nutr Metab 2003;16:134-7.

40. Habib GS, Nashashibi M, Saliba W, et al. Diabetic muscular infarction: emphasis on pathogenesis. Clin Rheumatol 2003;22:450-1.

41. Hachwi RN, Whitaker $\mathrm{CH}$, Felice KJ. Multiple recurrences of diabetic muscle infarction: case report and literature review. J Clin Neuromuscul Dis 2003;5:96-102.

42. Delis S, Ciancio G, Casillas J, et al. Diabetic muscle infarction after simultaneous pancreas-kidney transplant. Clin Transplant 2002;16:295-300.

43. Chow KM, Szeto CC, Griffith JF, et al. Unusual muscle pain in two patients with diabetic renal failure. Hong Kong Med J 2002;8:368-71.

44. Miller JW, Fleckenstein $\mathrm{J}$, Nodera $\mathrm{H}$, et al. MRI in diabetic muscle infarction. Neurology 2003;60:1019.

45. Melikian N, Bingham J, Goldsmith DJ. Diabetic muscle infarction: an unusual cause of acute limb swelling in patients on hemodialysis. Am J Kidney Dis 2003;41:1322-6.

46. Sharma P, Mangwana S, Kapoor RK. Diabetic muscle infarction: atypical MR appearance. Skeletal Radiol 2000;29:477-80.

47. Palmer GW, Greco TP. Diabetic thigh muscle infarction in association with antiphospholipid antibodies. Semin Arthritis Rheum 2001;30:272-80.

48. Silberstein L, Britton KE, Marsh FP, et al. An unexpected cause of muscle pain in diabetes. Ann Rheum Dis 2001;60:310-12.

49. Yoo WH, Kim CH, Park JH, et al. Case report: diabetic muscle infarction presenting as knee arthralgia. Rheumatol Int 2001;21:36-9.

50. Pedicelli A, Belli $P$, Fratino $M$, et al. Diabetic muscle infarction. Am J Med 2001;111:671-2.

51. Maclsaac J, Jerums G, Scurrah L. Diabetic muscle infarction. Med $J$ Aust 2002;177:323-4.

52. Lafforgue $\mathrm{P}$, Janand-Delenne B, Lassman-Vague $\mathrm{V}$, et al. Painful swelling of the thigh in a diabetic patient: diabetic muscle infarction. Diabetes Metab 1999;25:255-60.

53. Spengos K, Wohrle JC, Binder J, et al. Bilateral diabetic infarction of the anterior tibial muscle. Diabetes Care 2000;23:699-701.

54. Allali $F$, el Idrissi Lamghari A, el Hamani $Z$, et al. Calf muscular infarction in a diabetic patient. Clin Exp Rheumatol 2000;18:540.

55. Singer S, Rosenberg AE. Case records of the Massachusetts General Hospital. Weekly clinicopathological exercises. Case 29-1997. A 54-year-old diabetic woman with pain and swelling of the leg. N Engl J Med 1997;337:839-45.

56. Heureux F, Nisolle JF, Delgrange E, et al. Diabetic muscle infarction: a difficult diagnosis suggested by magnetic resonance imaging. Diabet Med 1998;15:621-2.

57. Bingham C, Hilton DA, Nicholls AJ. Diabetic muscle infarction: an unusual cause of leg swelling in a diabetic on continuous ambulatory peritoneal dialysis. Nephrol Dial Transplant 1998;13:2377-9.

58. Taira M, Komiya I, Taira T, et al. A case of diabetic muscle infarction in Japan. Diabetic Med 1998:15:1065-7.

59. Sagar M, Bowerfind WM, Wigley FM. A man with diabetes and a swollen leg. Lancet 1999;353:116.

60. Morcuende JA, Dobbs MB, Crawford H, et al. Diabetic muscle infarction. lowa Orthop J 2000;20:65-74.

61. Umpierrez GE, Stiles RG, Kleinbart J, et al. Diabetic muscle infarction. Am J Med 1996;101:245-50.

62. Chason DP, Fleckenstein JL, Burns DK, et al. Diabetic muscle infarction: radiologic evaluation. Skeletal Radiol 1996;25:127-32.

63. Chester CS, Banker BQ. Focal infarction of muscle in diabetics. Diabetes Care 1986;9:623-30.

64. Lauro GR, Kissel JT, Simon SR. Idiopathic muscular infarction in a diabetic patient. Report of a case. J Bone Joint Surg Am 1991;73:301-4.

65. Barton KL, Palmer BF. Bilateral infarction of the vastus lateralis muscle in a diabetic patient: a case report and review of the literature. J Diabetes Complications 1993;7:221-3.

66. Bodner RA, Younger DS, Rosoklija G. Diabetic muscle infarction. Muscle Nerve 1994;17:949-50.

67. Bjornskov EK, Carry MR, Katz FH, et al. Diabetic muscle infarction: a new perspective on pathogenesis and management. Neuromuscul Disord 1995:5:39-45.

68. Van Slyke MA, Ostrov BE. MRI evaluation of diabetic muscle infarction. Magn Reson Imaging 1995;13:325-9.

69. Vande Berg B, Malghem J, Puttemans T, et al. Idiopathic muscular infarction in a diabetic patient. Skeletal Radiol 1996;25:183-5.

70. Keller DR, Erpelding M, Grist T. Diabetic muscular infarction. Preventing morbidity by avoiding excisional biopsy. Arch Intern Med 1997;157:1611. 
71. Khoury NJ, el-Khoury GY, Kathol MH. MRI diagnosis of diabetic muscle infarction: report of two cases. Skeletal Radiol 1997;26:122-7.

72. Bhasin R, Ghobrial I. Diabetic myonecrosis: a diagnostic challenge in patients with long-standing diabetes. J Community Hosp Intern Med Perspect 2013;3:20494.

73. Sran S, Sran M, Ferguson N, et al. Diabetic myonecrosis: uncommon complications in common diseases. Case Rep Endocrinol 2014;2014:175029.

74. Ali O, Narshi C, Khanna M, et al. A painful swollen thigh in a diabetic patient: diabetic myonecrosis. Lancet 2014;383:1860.

75. Hoyt JR, Wittich CM. Diabetic myonecrosis. J Clin Endocrinol Metab 2008;93:3690.

76. Nagdev A, Murphy M, Sisson C. Bedside ultrasound for the detection of diabetic myonecrosis. Ann J Emerg Med 2008;26:969. e3-4.

77. Khan S, Al-Riyami D, Al-Ghailani M, et al. An under-recognized complication: diabetic myonecrosis. Oman Med J 2009;24: 228-30.

78. Mukhopadhyay P, Barai R, Philips CA, et al. An unusual case of myonecrosis. Case Rep Endocrinol 2011;2011:624020.

79. Bunch TJ, Birskovich LM, Eiken PW. Diabetic myonecrosis in a previously healthy woman and review of a 25-year Mayo Clinic experience. Endocr Pract 2002;8:343-6.

80. Reyes-Balaguer J, Solaz-Moreno E, Morata-Aldea C, et al. Spontaneous diabetic myonecrosis. Diabetes Care 2005;28: 980-1.

81. Wintz RL, Pimstone KR, Nelson SD. Detection of diabetic myonecrosis. Complication is often-missed sign of underlying disease. Postgrad Med 2006;119:66-9.

82. Muzaffar TH, Muzaffar FJ. A rare complication of diabetes mellitus in a 65-year-old man. J Diabetes Complications 2009;23:438-40.

83. Choudhury BK, Saikia UK, Sarma D, et al. Diabetic myonecrosis: an underreported complication of diabetes mellitus. Indian $J$ Endocrinol Metab 2011;15(Suppl 1):S58-61.

84. Kim SW, Kim SS. Myonecrosis of paralumbar spine muscle. Spine 2011;36:E1162-5.

85. Rastogi A, Bhadada SK, Saikia UN, et al. Recurrent diabetic myonecrosis: a rare complication of a common disease. Indian $\mathrm{J}$ Med Sci 2011:65:311-15.

86. Rashidi A, Bahrani O. Diabetic myonecrosis of the thigh. $J$ Clin Endocrinol Metab 2011:96:2310-11.

87. Welck MJ, Vetpillai P, Balaji V, et al. Recurrent multifocal diabetic myonecrosis: a cause of severe extremity pain in a diabetic patient Ann R Coll Surg Engl 2013;95:e5-6.

88. Chalasani S, Bettadahalli SS, Bhupathi SV, et al. A novel case of diabetic muscle necrosis in a patient with cystic fibrosis-related diabetes. Clin Med Res 2013;11:113-16.
89. Martinez JH, Torres O, Mangual Garcia MM, et al. Diabetic myonecrosis: an atypical presentation. Case Rep Endocrinol 2013;2013:190962.

90. Carden DL, Granger DN. Pathophysiology of ischaemia-reperfusion injury. J Pathol 2000;190:255-66.

91. Mohamed SM, Abdou MO, Assem HM, et al. Anticardiolipin antibodies in children with insulin-dependent diabetes mellitus. Metabolism 2002;51:1148-52.

92. Lorini R, d'Annunzio G, Montecucco C, et al. Anticardiolipin antibodies in children and adolescents with insulin-dependent diabetes mellitus. Eur J Pediatr 1995;154:105-8.

93. Auburger G, Gispert S, Lahut S, et al. 12q24 locus association with type 1 diabetes: SH2B3 or ATXN2? World J Diabetes 2014;5:316-27.

94. Calvo-Romero JM, Lima-Rodriguez EM. Anticardiolipin antibodies in patients with type 2 diabetes mellitus. Clin Med Res 2009;7:93-5.

95. Goswami P, Baruah MP. The role of MRI in diagnosis of diabetic muscle infarction: an underdiagnosed entity. Int $J$ Endocrinol Metab 2011;9:353-5

96. Delaney-Sathy LO, Fessell DP, Jacobson JA, et al. Sonography of diabetic muscle infarction with MR imaging, CT, and pathologic correlation. Am J Roentgenol 2000;174:165-9.

97. Kapur S, McKendry RJ. Treatment and outcomes of diabetic muscle infarction. J Clin Rheumatol 2005;11:8-12.

98. Barohn RJ, Kissel JT. Case of the month: painful thigh mass in a young woman: diabetic muscle infarction. Muscle Nerve 1992;15:850-5.

99. Onyenemezu I, Capitle E Jr. Retrospective analysis of treatment modalities in diabetic muscle infarction. Open Access Rheumatol Res Rev 2014;6:1-6.

100. Gargiulo P, Schiaffini R, Bosco D, et al. Diabetic microangiopathy: lupus anticoagulant dependent thrombotic tendency in type 1 (insulin-dependent) diabetes mellitus. Diabetic Med 1997;14:132-7.

101. Hirsh J, Dalen JE, Fuster V, et al. Aspirin and other platelet-active drugs. The relationship among dose, effectiveness, and side effects. Chest 1995;108(4 Suppl):247S-57S

102. Sun W, Gerhardinger C, Dagher Z, et al. Aspirin at low-intermediate concentrations protects retinal vessels in experimental diabetic retinopathy through non-platelet-mediated effects. Diabetes 2005:54:3418-26.

103. Kern TS, Engerman RL. Pharmacological inhibition of diabetic retinopathy: aminoguanidine and aspirin. Diabetes 2001:50:1636-42.

104. DAMAD Study Group. Effect of aspirin alone and aspirin plus dipyridamole in early diabetic retinopathy. A multicenter randomized controlled clinical trial. Diabetes 1989;38:491-8. 